\title{
Isothermal and Non-Isothermal Crystallization Kinetics of Conductive Polyvinylidene Fluoride/Poly(Ethylene Terephthalate) Based Composites
}

\author{
Nafaa Athmouni1,2, Jianbin Song2,3, Frej Mighri1,2, Saïd Elkoun ${ }^{1,4}$ \\ ${ }^{1}$ Research Center for High Performance Polymer and Composite Systems, CREPEC, Laval University, Quebec, \\ Canada \\ ${ }^{2}$ Department of Chemical Engineering, Laval University, Quebec, Canada \\ ${ }^{3}$ Department of Material Science and Technology, Nanjing University of Technology, Nanjing, China \\ ${ }^{4}$ Department of Mechanical Engineering, Sherbrooke University, Sherbrooke, Canada \\ Email: Frej.Mighri@gch.ulaval.ca
}

Received 5 November 2015; accepted 25 January 2016; published 28 January 2016

Copyright (C) 2016 by authors and Scientific Research Publishing Inc.

This work is licensed under the Creative Commons Attribution International License (CC BY).

http://creativecommons.org/licenses/by/4.0/

(c) (i) Open Access

\section{Abstract}

This work deals with isothermal and non-isothermal crystallization kinetics of electrically conductive polyvinylidene fluoride/poly(ethylene terephthalate) (PVDF/PET) based composites. It completes our previous work in which we related the crystallinity of these conductive PVDF/PET based composites to their through-plane resistivity [1]. Isothermal crystallization was described using the logarithmic form of the Avrami equation and it was observed that the crystallization rate of the PVDF phase inside the composite became slower compared to that of neat PVDF. In nonisothermal crystallization, the Avrami exponent of PVDF phase did not show any noticeable variation; however, that of PET phase, which contains the major part of the conductive carbon black (CB) and graphite (GR) additives, showed an evident decrease compared with neat PET. It was also observed that, at the same cooling rate, the crystallization rate of PVDF and PET phases inside the composite was slower than that of neat PVDF and PET.

\section{Keywords}

Isothermal Crystallization, Non-Isothermal Crystallization, PVDF, PET, Crystallization Kinetics, Avrami Model, Bipolar Plate 


\section{Introduction}

A PEMFC is a type of fuel cell that transforms, via an electrochemical reaction, chemical energy into electricity. This technology is believed to be a promising source of clean energy in the future. Due to their special characteristics, PEMFCs are candidates for automotive applications, small-scale stationary power generation and portable power applications. However, due to their high price, their application on a large scale stills very low. PEMFCs are constituted of MEA (membrane electrode assembly), GDL (gas diffusion layer), and bipolar plates (BPs). Among these three main components, BPs are considered as the most important component in PEMFCs since they occupy around $80 \%$ of PEMFC stack volume, $60 \%-80 \%$ of its total weight and $40 \%-50 \%$ of its cost [2]. Thus, the development of appropriate and low cost materials for BPs becomes a key factor for PEMFCs commercialization.

To date, three types of materials are used for the fabrication of BPs [3]: metals or metal-based materials, graphite, and polymer composites. Polymer-based materials are deemed to be excellent materials for BPs owing to their good mechanical properties, corrosion resistance, low cost and ease of processing. Poly(methyl methacrylate) (PMMA), PVDF, PET, poly(styrene-co-acrylonitrile), nylon 6, polystyrene, poly(vinyl acetate), etc., have been used to prepare BPs for PEMFCs [4]. However, the addition of high concentrations of conductive fillers is required to ensure electrical conductivity and this leads to poor mechanical properties and machining problems.

It is well known that polymers properties are largely controlled by their crystallization conditions. The investigation of their crystallization behavior is then an important step to optimize many of their properties, such as mechanical properties and electrical conductivity. Polymer crystallization is centered mostly on isothermal and non-isothermal crystallizations (including nucleation, crystal growth, crystal size, and crystallization rate) since they are of great importance to reach the desired end-use properties. Among polymer materials for BP applications, PVDF-based blends with PMMA or PET are regarded as the most promising candidates because these two polymers exhibit good mechanical and electrical properties once appropriate conductive fillers are added. PVDF/PMMA blends were extensively studied as PMMA is miscible with PVDF. Reported works aimed at understanding the effect of PMMA content on PVDF/PMMA blend morphology, its rheological and thermo-mechanical properties, as well as miscibility, crystallinity, crystalline structure and crystallization kinetics of the PVDF phase [5] [6]. Unlike PMMA, PET is a semi-crystalline polymer and, once carbon conductive fillers are added to the PVDF/PET blend, morphology analysis revealed that that the conductive fillers are mainly confined in the PET phase. This peculiar morphology clearly yields to an improvement of PVDF/PET mechanical and electrical properties [7]. However and unlike PVDF/PMMA blends, there are few reported works on PVDF/PET crystallization [8] and, to the best of our knowledge, no detailed studies on the isothermal and non-isothermal crystallization kinetics of PVDF/PET based blends used for PEMFC bipolar plates, which represents the main objective of the present work. We based our study on a previous work [1] where we have developed PVDF/PET/ $\mathrm{CB} / \mathrm{GR}$ conductive composites, in which were added small amounts of TPO-RP to facilitate BPPs demolding and cyclic butylene terephthalate (c-BT) oligomer to decrease composites viscosity and consequently to improve their process ability. In that work, we showed the effect of PVDF and PET crystallinity and crystallization temperature on BP through-plane resistivity. In the present work, we show how this crystallinity is developed inside the conductive PVDF/PET based composite, especially under isothermal and non-isothermal conditions, which respectively represent the real conditions of BP molding and cooling.

Isothermal crystallization will be treated with the logarithmic form of the Avrami equation (Equation (1)) [9] [10] using the following four hypothesis: 1) the crystal growth rate, polymer density and the shape of the growing nuclei are constant; 2) uniqueness of nucleation; 3) no volume change during crystallization; and 4) no secondary crystallization.

$$
\ln [-\ln (1-X(t))]=\ln (Z)+n \ln (t)
$$

where $X(t)$ is the relative degree of crystallinity at a crystallization time $t(\mathrm{~s})$, and $n$ and $Z$ are respectively the Avrami exponent and the crystallization rate constant obtained directly from the plot of $\ln [-\ln (1-X(t))]$ versus $\ln (t)$.

The non-isothermal crystallization process could also be depicted by the above modified Avrami equation [11]. However, considering the effect of cooling or heating rate, Jeziorny [12] proposed a modified crystallization constant, $Z_{c}$, given as follows: 


$$
\log Z_{c}=\frac{\log Z}{\phi}
$$

where $\phi\left({ }^{\circ} \mathrm{C} / \mathrm{min}\right)$ corresponds to the cooling rate.

\section{Experimental}

\subsection{Materials Used and Composite Preparation}

PVDF (Kynar $\left.{ }^{\circledR} 720\right)$, having a density of $1.78 \mathrm{~g} / \mathrm{cm}^{3}$ and a melt flow index, MFI, of $7.0 \mathrm{~g} / 10 \mathrm{~min}\left(230^{\circ} \mathrm{C} / 3.8 \mathrm{~kg}\right.$, ASTM D1238), was purchased from Arkema, USA. PET (PET 9921w), with a density of $1.25 \mathrm{~g} / \mathrm{cm}^{3}$ and a MFI of $21.5 \mathrm{~g} / 10 \mathrm{~min}$, was kindly supplied by Eastman, USA. CB and GR conductive additives were Printex XE-2 (from Degussa-Hüls, Germany) and Timrex KS-75 (from Timcal America, USA), respectively. c-BT oligomer (160 Resin) having a room temperature Newtonian viscosity, $\eta$, of 0.02 Pa.s, was purchased from Cyclic Corporation, USA. The selection of the above polymers and additives was based on our previous experimental work [1] [13].

Firstly, PET and PVDF were dried under vacuum at $80^{\circ} \mathrm{C}$ for 24 hours, and then the PET, PVDF and the other additives were mixed at $280^{\circ} \mathrm{C}$ for $10 \mathrm{~min}$ in a laboratory internal mixer (Haake Buchler Rheocord system). The screw rotational speed was fixed at $50 \mathrm{rpm}$. After blending, the prepared composite was cut into small pieces for differential scanning calorimetry (DSC) characterization. Table 1 presents the composition of the conductive PVDF/PET based composites studied in this work.

\subsection{DSC Characterization}

The investigation on crystallization kinetics of the developed conductive PVDF/PET based composites was performed using a DSC Diamond apparatus, from Perkin Elmer. The weights of characterized samples were 3 - 4 mg. All the DSC runs were done under nitrogen $\left(\mathrm{N}_{2}\right)$ atmosphere. For the characterization of isothermal crystallization kinetics, the samples were quickly heated up to $280^{\circ} \mathrm{C}$ at a heating rate of $200^{\circ} \mathrm{C} / \mathrm{min}$ and held at this temperature for $10 \mathrm{~min}$, to eliminate the thermal history (Scheme 1). Then, samples were cooled to the desired PET pre-crystallization temperature at a cooling rate of $200^{\circ} \mathrm{C} / \mathrm{min}$ and held at this temperature for $20 \mathrm{~min}$. The studied PET pre-crystallization temperatures were $190^{\circ} \mathrm{C}$ and $180^{\circ} \mathrm{C}$ at which only PET phase may crystallize and PVDF phase is still in the melted state (Scheme 1(a)). So we could study in this case the influence of PET pre-crystallization on further PVDF isothermal crystallization, and the corresponding crystallization data are labeled $\mathrm{PVDF}_{\mathrm{PET} 190}$ and $\mathrm{PVDF}_{\mathrm{PET} 180}$. After PET phase isothermal crystallization at the two temperatures mentioned above, samples were cooled at $-200^{\circ} \mathrm{C} / \mathrm{min}$ for further PVDF phase isothermal crystallization. The PVDF phase isothermal crystallization temperatures studied were $138^{\circ} \mathrm{C}, 140^{\circ} \mathrm{C}, 142^{\circ} \mathrm{C}$ and $144^{\circ} \mathrm{C}$ (Scheme 1 (a)). Another crystallization data, labeled $\mathrm{PVDF}_{\mathrm{PET} 280}$, corresponds to samples cooled directly from $280^{\circ} \mathrm{C}$ at $-200^{\circ} \mathrm{C} / \mathrm{min}$ to the above PVDF crystallization temperatures without any PET phase pre-crystallization (Scheme $1(\mathrm{~b}))$.

For non-isothermal crystallization, samples were quickly heated to $280^{\circ} \mathrm{C}$ at a heating rate of $200^{\circ} \mathrm{C} / \mathrm{min}$, held at that temperature for $10 \mathrm{~min}$, and then cooled to room temperature at four various cooling rates of 5, 10, 20 and $40^{\circ} \mathrm{C} / \mathrm{min}$.

Table 1. Weight composition of the studied conductive PVDF/PET based composite.

\begin{tabular}{ccc}
\hline Composite components & \multicolumn{2}{c}{ Weight composition (wt\%) } \\
\hline PVDF & 39.7 & 70.9 \\
PET & 31.2 & \\
CB & 14.9 & 20.5 \\
GR & 5.6 & \\
C-BT & 3.7 & 3.7 \\
TPO-RP & 4.9 & 4.9 \\
\hline
\end{tabular}




\section{Results and Discussion}

\subsection{Melting Behavior of the Developed Conductive PVDF/PET Composites}

Figure 1 shows the heating DSC curve (second heating) of the conductive PVDF/PET based composite obtained at a heating rate of $10^{\circ} \mathrm{C} / \mathrm{min}$. The sample was firstly heated to $280^{\circ} \mathrm{C}$, held at this temperature for $10 \mathrm{~min}$, then cooled to room temperature at a cooling rate of $-40^{\circ} \mathrm{C} / \mathrm{min}$, and finally heated again to $280^{\circ} \mathrm{C}$ at the same heating rate of $10^{\circ} \mathrm{C} / \mathrm{min}$. As shown, two melting peaks appear at $164.5^{\circ} \mathrm{C}$ and $231^{\circ} \mathrm{C}$, corresponding to the melting of PVDF and PET phases, respectively. It is obvious that these melting temperatures are lower than those of neat PVDF $\left(170^{\circ} \mathrm{C}\right)$ [14] and neat PET $\left(247^{\circ} \mathrm{C}\right)$ [11]. This decrease is due to the formation of unstable and imperfect crystals inside PVDF and PET phases largely influenced by the presence of the solid CB and GR additives.

\subsection{Isothermal Crystallization Kinetics of the Developed Conductive PVDF/PET Based Composites}

For semi-crystalline polymers, the crystallization mechanism includes two steps (nucleation and crystal growth), which control the crystallization rate, as depicted in Figure 2. In the nucleation region, where the nucleation rate

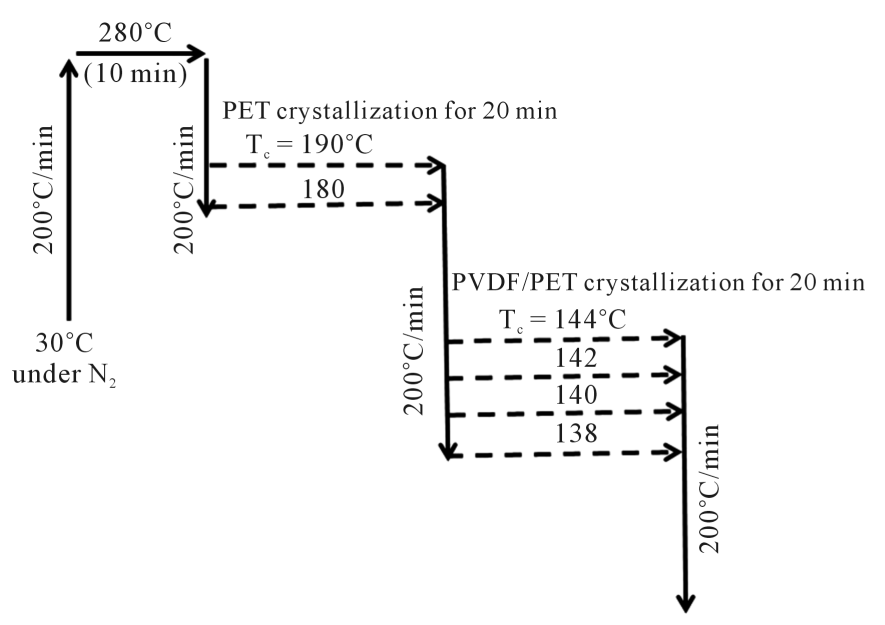

(a)

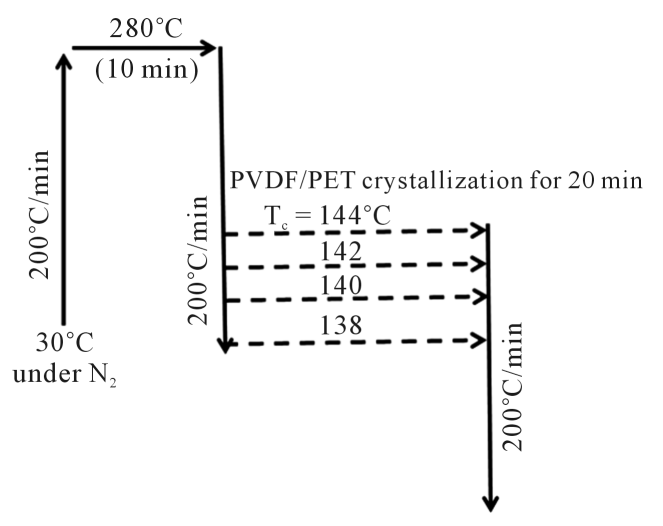

(b)

Scheme 1. DSC temperature profile: (a) with PET pre-crystallization at $190^{\circ} \mathrm{C}$ and $180^{\circ} \mathrm{C}$; and (b) without PET pre-crystallization.

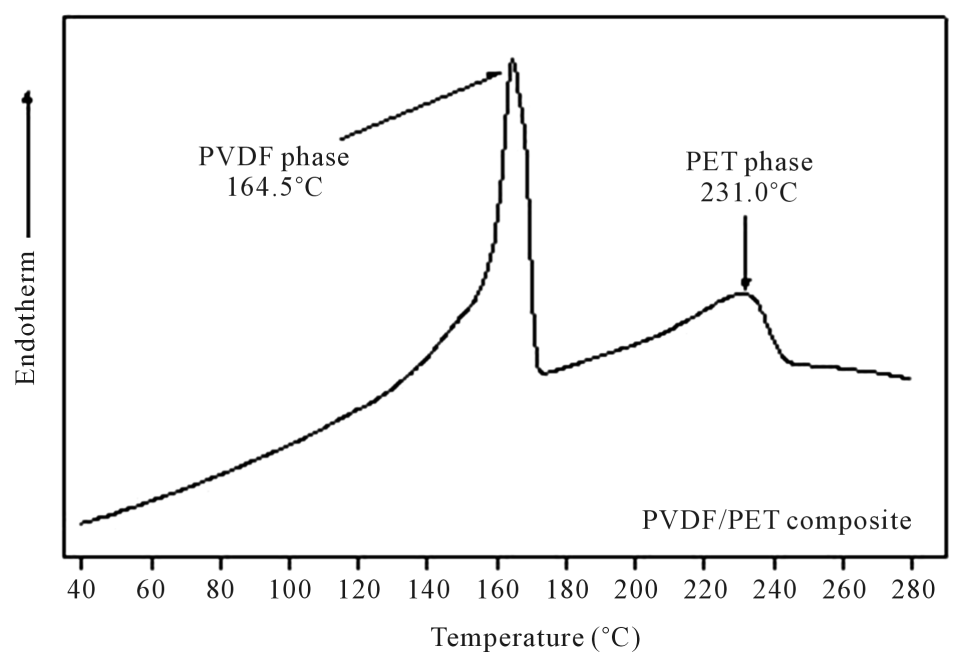

Figure 1. DSC curve of conductive PVDF/PET based composite (heating rate of $\left.10^{\circ} \mathrm{C} / \mathrm{min}\right)$. 


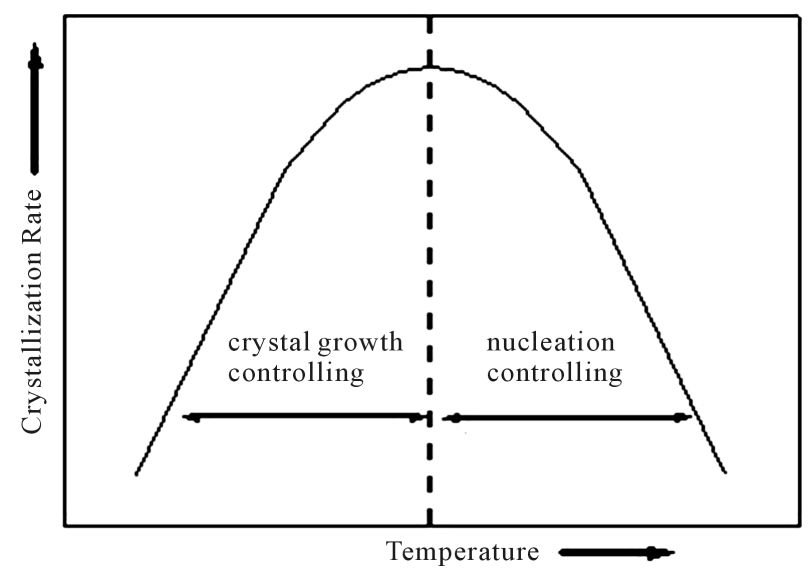

Figure 2. Crystallization rate as a function of temperature for semi-crystalline polymers.

is slow and the rate of crystal growth is large, the whole crystallization is consequently controlled by the nucleation process and the crystallization rate decreases with increasing the temperature. However, in the crystal growth region, the crystallization process is mainly controlled by secondary nucleation and chain diffusion and consequently, the entire crystallization rate increases with increasing the crystallization temperature.

The isothermal crystallization kinetic of the PVDF phase inside the conductive composite was studied at four crystallization temperatures $\left(138^{\circ} \mathrm{C}, 140^{\circ} \mathrm{C}, 142^{\circ} \mathrm{C}\right.$ and $\left.144^{\circ} \mathrm{C}\right)$. For the sake of comparison, the isothermal crystallization kinetic of neat PVDF was also investigated. In the present work, we focused on PVDF phase crystallization only, since PET phase crystallization is very low and consequently, its diffused heat could not be easily detected by the DSC. Figure 3 shows the plots of $\ln [-\ln (1-X(t))]$ versus $\ln t$ for neat PVDF and the conductive PVDF/PET based composite, and the corresponding Avrami parameters of their isothermal crystallization are summarized in Table 2. It is obvious that the crystallization rate constant $z$ decreases with increasing the crystallization temperature for both neat PVDF and conductive PVDF/PET based composite, which, in the light of Figure 2, indicates that the crystallization process is mainly controlled by the nucleation process, mainly due to the presence of solid CB and GR particles, which play the role of nucleating agents. As shown in Table 2, the Avrami exponent $\mathrm{n}$, regarding to nucleation and crystal growth mechanisms, presents only a small variation (n varies between 2 and 3) for all studied crystallization temperatures. So the developed spherulites inside the PET phase, which is rich with CB and GR additives, didn't have any significant influence on spherulite growth inside the PVDF phase, less rich with CB and GR additives [1] [11]. Due to the fact that polymer isothermal crystallization is very complex (e.g., the crystal growth rate is not constant, the shape of crystals is not always the same, the existence of secondary crystallization, etc.), this causes Avrami exponent to be decimal, not integer.

It is interesting to note that neat PVDF can crystallize freely when cooled from its melted state. However, for the conductive PVDF/PET based composite with PET pre-crystallization at $190^{\circ} \mathrm{C}\left(\mathrm{PVDF}_{\mathrm{PET} 190}\right)$ and at $180^{\circ} \mathrm{C}$ $\left(\mathrm{PVDF}_{\mathrm{PET180}}\right)$, some PET crystallinity is already developed inside the PET phase before the PVDF phase begins to crystallize. The fact that the Avrami exponents $n$ are still between 2 and 3 is an indication that PET crystallization didn't change the nucleation and growth mechanisms of PVDF spherulites. This is mainly due to the fact that, taking into account the localization of the CB and GR additives inside the PVDF phase, the latter constitutes the matrix (continuous) phase and consequently, the PVDF macromolecular chains are not significantly restricted in motion by the discontinuous PET phase.

By using the Avrami equation (Equation (1)), we could obtain the half-time of crystallization, $t_{1 / 2}$ (s), defined as the time at which $50 \%$ of total crystallization is completed.

$$
t_{1 / 2}=\left(\frac{\ln 2}{Z}\right)^{1 / n}
$$

This equation is used to describe the crystallization rate, $G\left(\mathrm{~s}^{-1}\right)$, given by the following relation:

$$
G=\left(t_{1 / 2}\right)^{-1}
$$



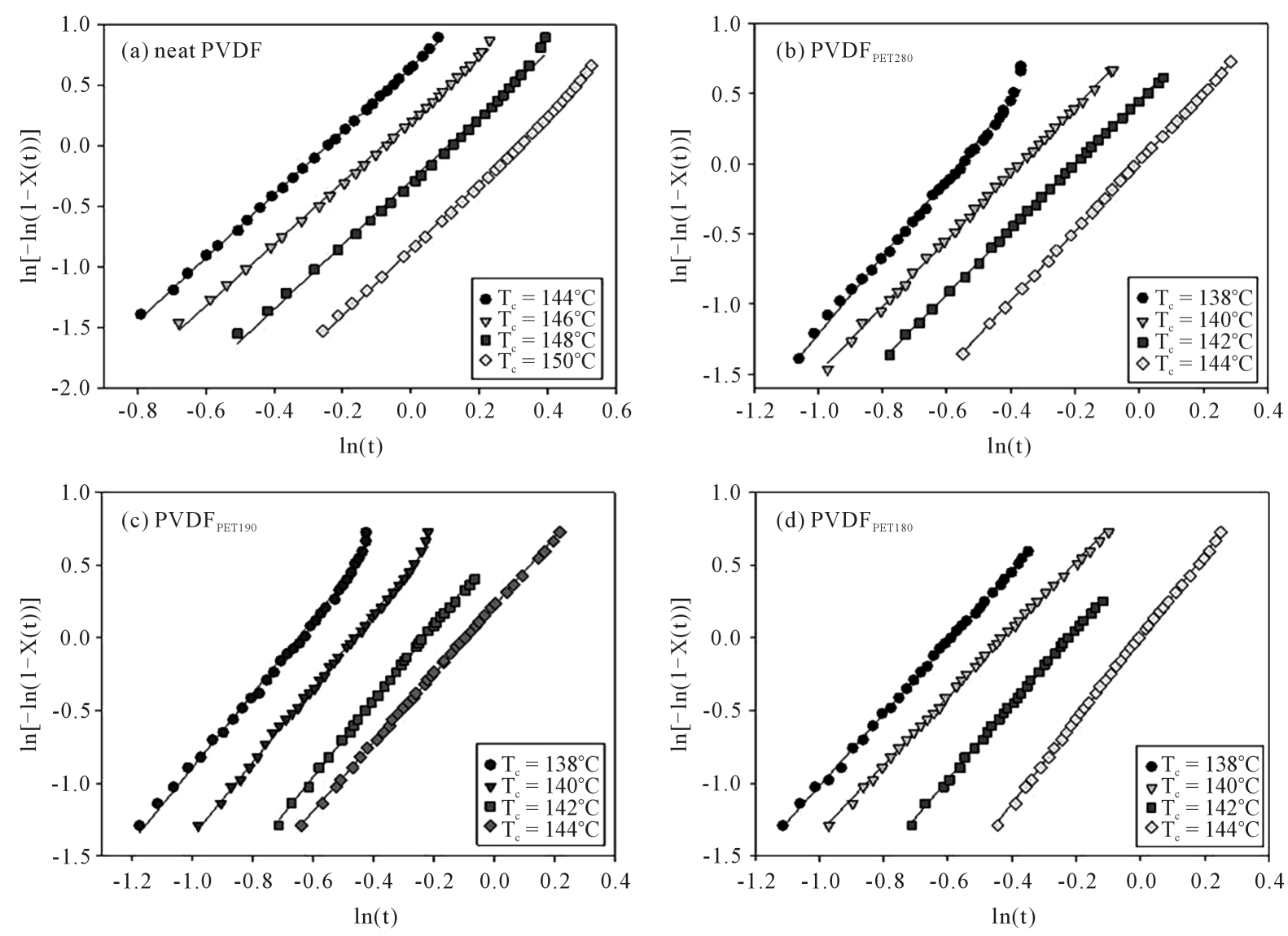

Figure 3. $\ln [-\ln (1-X(t))]$ versus $\ln (t)$ at different crystallization temperatures: (a) neat PVDF; (b) PVDF/PET based composite without PET pre-crystallization; (c) PVDF/PET based composite with PET pre-crystallization at $190^{\circ} \mathrm{C}$; and (d) $\mathrm{PVDF} / \mathrm{PET}$ based composite with PET pre-crystallization at $180^{\circ} \mathrm{C}$.

The values of $t_{1 / 2}$ and $G$ for neat PVDF and PVDF phase inside the conductive PVDF/PET based composite are listed in Table 2 and the relation between $G\left(\mathrm{~s}^{-1}\right)$ and the crystallization temperature, $T_{c}(\mathrm{~K})$, is shown in Figure 4.

As mentioned above, PET crystallization is very difficult to be observed in isothermal crystallization. So we firstly supposed here that the crystallization rate of the whole composite is controlled by the crystallization of PVDF phase only. This supposition is clearly supported by Figure 4 where we can see that for the two PET pre-crystallization temperatures $\left(180^{\circ} \mathrm{C}\right.$ and $\left.190^{\circ} \mathrm{C}\right)$, there is no significant different between $G$ (PVDF ${ }_{\text {PET190) }}$ and $G\left(\mathrm{PVDF}_{\mathrm{PET} 180}\right)$. Also, it can be seen from Figure 4 that the crystallization rate decreases with increasing the crystallization temperature, which is an indication that the composite crystallization was mainly controlled by the nucleation process, as already sketched in Figure 1. For the three composites, it is evident that, due to PET pre-crystallization, $\mathrm{PVDF}_{\mathrm{PET} 190}$ and $\mathrm{PVDF}_{\mathrm{PET} 180}$ have more crystals than PVDF PET280. $_{\text {. }}$

In order to further study the effect of PET phase and CB and GR additives on the isothermal crystallization of the PVDF phase, the isothermal crystallization activation energy, $\Delta E$, was determined using the following Arrhenius equation [15]:

$$
Z^{1 / n}=Z_{0} \exp \left(-\frac{\Delta E}{R T_{c}}\right)
$$

which is rewritten as follows:

$$
\frac{\ln Z}{n}=\ln Z_{0}-\frac{\Delta E}{R T_{c}}
$$


Table 2. Isothermal crystallization kinetic parameters for neat PVDF and conductive PVDF/PET based composite crystallized at different temperatures.

\begin{tabular}{cccccc}
\hline & $T_{c}\left({ }^{\circ} \mathrm{C}\right)$ & $n$ & $Z$ & $t_{1 / 2}(\mathrm{~s})$ & $G\left(\mathrm{~s}^{-1}\right)$ \\
\hline \multirow{4}{*}{ Neat PVDF } & 144 & 2.6 & 4.2 & 0.49 & 2.04 \\
& 146 & 2.2 & 1.2 & 0.80 & 1.25 \\
& 148 & 2.4 & 0.5 & 1.20 & 0.83 \\
& 150 & 2.6 & 0.1 & 1.87 & 0.53 \\
\hline PVDF $_{\text {PET280 }}$ & 138 & 2.6 & 25.6 & 0.25 & 4.07 \\
& 140 & 2.3 & 6.2 & 0.38 & 2.62 \\
& 142 & 2.4 & 3.2 & 0.77 & 1.30 \\
& 144 & 2.5 & 1.0 & 0.85 & 1.18 \\
\hline & 138 & 2.3 & 28.8 & 0.20 & 4.93 \\
& 140 & 2.6 & 15.3 & 0.30 & 3.36 \\
& 142 & 2.53 & 3.72 & 0.52 & 1.94 \\
& 144 & 2.38 & 1.65 & 0.86 & 1.17 \\
\hline PVDF $_{\text {PET180 }}$ & 148 & 2.64 & 45.19 & 0.21 & 4.85 \\
& 140 & 2.59 & 15.38 & 0.30 & 3.31 \\
& 144 & 2.51 & 3.39 & 0.53 & 1.88 \\
& 2.99 & 1.08 & 0.86 & 1.16 \\
\hline
\end{tabular}

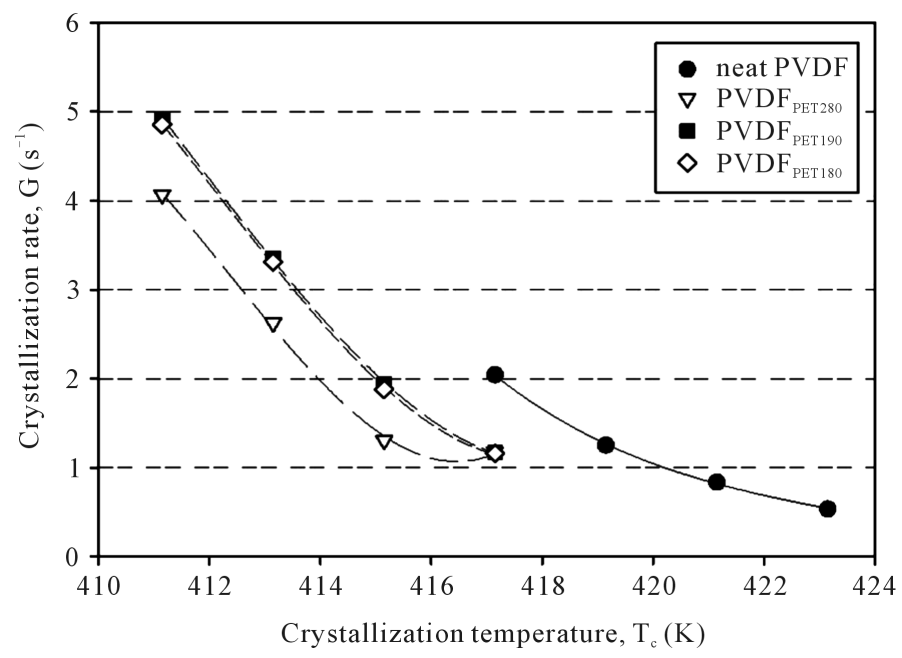

Figure 4. Crystallization rate as a function of crystallization temperature $T_{c}(\mathrm{~K})$ for neat PVDF and PVDF phase in the conductive PVDF/PET based composite.

where $Z_{0}$ is a temperature-independent pre-exponential factor, $T_{c}$ is the isothermal crystallization temperature $(\mathrm{K})$, and $R(\mathrm{~J} / \mathrm{mol} \cdot \mathrm{K})$ ) is the universal gas constant. Figure 5 shows the plots of $\ln Z / n$ versus $1 / T_{c}$ for neat PVDF, PVDF $F_{\mathrm{PET} 180}, \mathrm{PVDF}_{\mathrm{PET} 190}$ and $\mathrm{PVDF}_{\mathrm{PET} 280}$. The corresponding isothermal crystallization activation energies, obtained from the slope of the curves, are $-322 \mathrm{~kJ} / \mathrm{mol}$ (for neat PVDF), $-344 \mathrm{~kJ} / \mathrm{mol}$ (for PVDF ${ }_{\mathrm{PET} 180}$ ), $-300 \mathrm{~kJ} / \mathrm{mol}$ (for $\mathrm{PVDF}_{\mathrm{PET} 190}$ ), and $-290 \mathrm{~kJ} / \mathrm{mol}$ (for $\mathrm{PVDF}_{\mathrm{PET} 280}$ ) (Nb: the minus sign is due to the fact that, for 


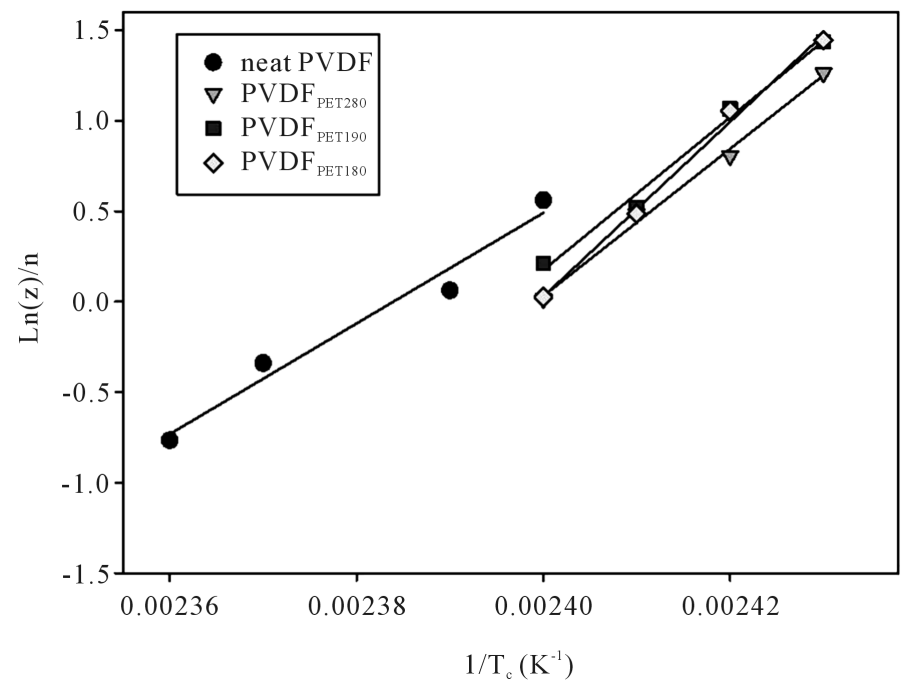

Figure 5. Plot of $\ln Z / n$ versus $1 / T_{c}$ (from Arrhenius Equation (6)) for neat PVDF and PVDF ${ }_{\text {PET190, }} \mathrm{PVDF}_{\text {PET180 }}$ and $\mathrm{PVDF}_{\mathrm{PET} 280 .}$

the crystallization temperatures, $T_{c}$, studied, the crystallization rate decreases with increasing $T_{c}$ ).

For $\mathrm{PVDF}_{\mathrm{PET190}}$, the crystallization activation energy was lower than that of $\mathrm{PVDF}_{\mathrm{PET} 180}$ because, as shown in Table 2, the crystallization rate of $\mathrm{PVDF}_{\mathrm{PET} 190}$ was quicker than that of PVDF $\mathrm{PET180}_{0}$. However, for PVDF $\mathrm{PET280}_{\text {, }}$ the isothermal crystallization activation energy is not expected to exceed those of $\mathrm{PVDF}_{\mathrm{PET} 190}$ and $\mathrm{PVDF}_{\mathrm{PET} 180}$. We think that this is possibly related to the crystallization of PET phase when cooled from the melted state to the crystallization temperature. As mentioned before, $\mathrm{PVDF}_{\mathrm{PET} 190}$ and $\mathrm{PVDF}_{\mathrm{PET180}}$, were firstly cooled to 190 and $180^{\circ} \mathrm{C}$, respectively, and then held at these temperatures for 20 min where a big part of PET phase will crystallize. When samples were cooled further to around $140^{\circ} \mathrm{C}$, the PET will not continue to crystallize. However, in $\mathrm{PVDF}_{\mathrm{PET} 280}$, the sample was rapidly cooled to $140^{\circ} \mathrm{C}$ from melt $\left(280^{\circ} \mathrm{C}\right)$, giving less chance to PET to crystallize. As a result, the isothermal crystallization activation energy of PVDF phase is decreased compared to neat PVDF.

\subsection{Non-Isothermal Crystallization Kinetic of the Developed Conductive PVDF/PET Based Composite}

DSC cooling curves of neat PVDF and conductive PVDF/PET based composite are respectively shown in Figure 6(a) and Figure 6(b) for different cooling rates $\left(5^{\circ} \mathrm{C}, 10^{\circ} \mathrm{C}, 20^{\circ} \mathrm{C}\right.$ and $\left.40^{\circ} \mathrm{C}\right)$. Both figures show that, as the cooling rate is increased, the exothermic crystallization peaks were shifted to lower temperatures and became broader. They also show that the amount of heat released upon crystallization decreased as cooling rates increased. Because the mobility and flexibility of the PVD and PET chains decreased at higher cooling rates, their chain segments took a longer time to crystallize, which further lowered their crystallization temperatures $T_{c}$. Table 3 reports the values of $T_{c}$ (which could be used to roughly measure the nucleation rate [15]) for neat PVDF (obtained from Figure 6(a)) and those of PVDF and PET phases inside the PVDF/PET based composite (obtained from Figure 6(b)). Also, $T_{c}$ of PVDF phase inside the blend is lower than that of neat PVDF at the same cooling rate, which is an indication that the ability of PVDF phase to nucleate inside the blend was decreased.

Figure 7(a), Figure 7(b) and Figure 7(c) show respectively the plots of $\ln [-\ln (1-X(t))]$ versus $\log t$ for neat PVDF, and PVDF and PET phases inside the conductive PVDF/PET based composite. Their corresponding Avrami exponents, $n$, modified crystallization constants, $Z_{c}$ (obtained from Equation (2)), and crystallization rate constants, $G\left(\mathrm{~s}^{-1}\right)$, obtained from the initial portion of the curves, are shown in Table 3 . For the different cooling rates, $n$ ranged from 3.9 to 4.6 for neat PVDF and from 4.2 to 5.3 for PVDF phase inside the conductive PVDF/PET based composite. This is an indication that the nucleation and crystal growth processes for PVDF didn't change in the two cases. However, the Avrami exponent for PET phase, which varied between 2.5 and 3.4, showed an important decrease compared to neat PET, where the Avrami exponent varied between 4.5 and 6.7 [16]. This could be due to the fact that PET spherulites underwent a three-dimension growth process. On the 


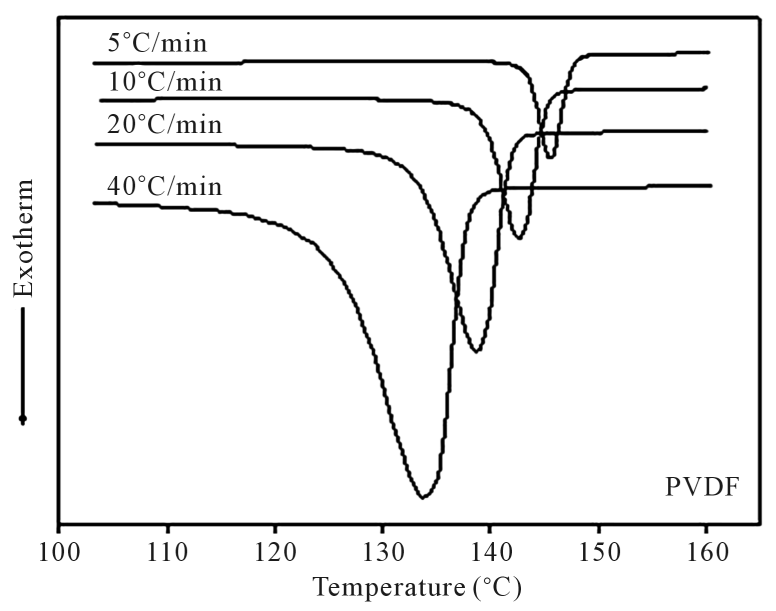

(a)

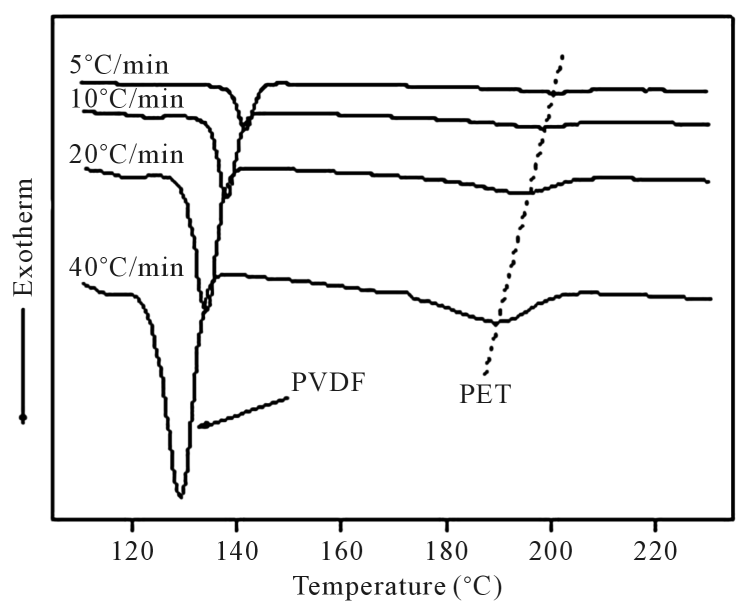

(b)

Figure 6. Cooling DSC curves at different cooling rates: (a) Neat PVDF, and (b) conductive PVDF/PET based composite.

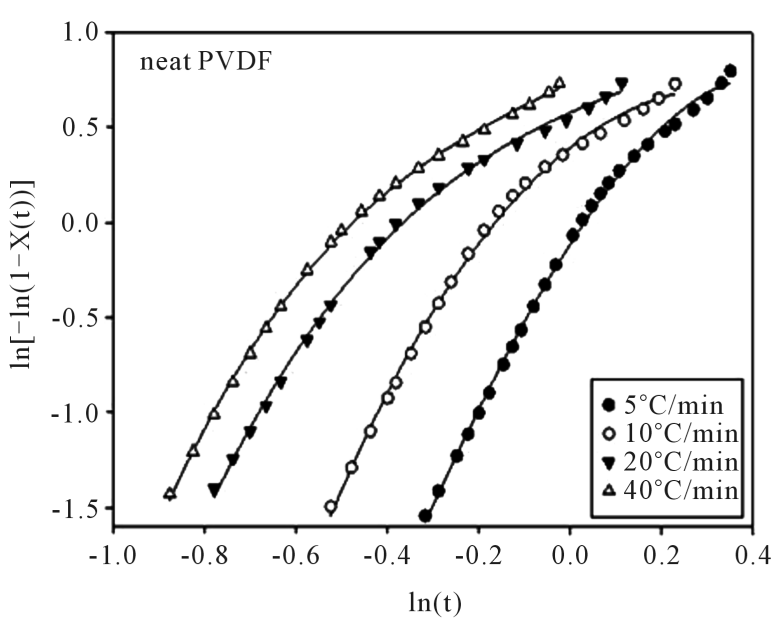

(a)

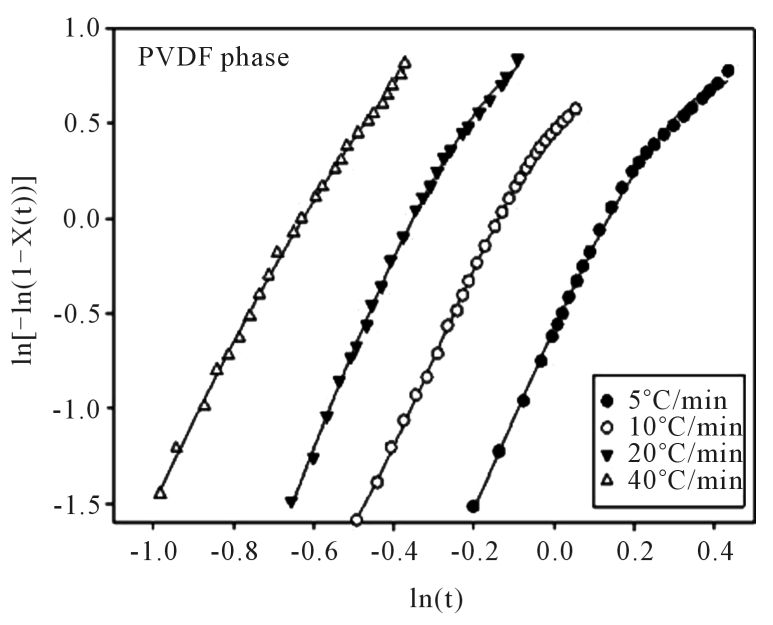

(b)

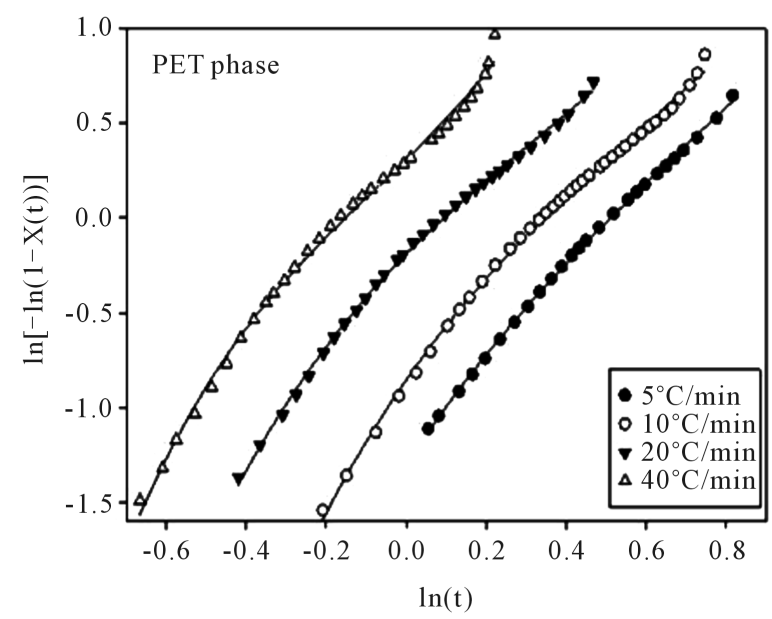

(c)

Figure 7. Plots of $\ln [-\ln (1-X(t))]$ versus $\log t$ for non-isothermal crystallization: (a) neat PVDF; (b) and (c) respectively PVDF and PET phases inside the conductive PVDF/PET based composite. 
Table 3. The data of $T_{c}$ and non-isothermal crystallization kinetics for neat PVDF, and PVDF and PET phases in the conductive PVDF/PET based composite.

\begin{tabular}{|c|c|c|c|c|c|c|}
\hline & & $\Phi\left({ }^{\circ} \mathrm{C} / \mathrm{min}\right)$ & $T_{c}\left({ }^{\circ} \mathrm{C}\right)$ & $n$ & $Z_{c}$ & $t_{1 / 2}(\mathrm{~s})$ \\
\hline \multirow{4}{*}{\multicolumn{2}{|c|}{ Neat PVDF }} & 5 & 146 & 4.6 & 0.96 & 58 \\
\hline & & 10 & 143 & 4.6 & 1.23 & 35 \\
\hline & & 20 & 139 & 3.9 & 1.20 & 21 \\
\hline & & 40 & 134 & 4.3 & 1.14 & 16 \\
\hline \multirow{8}{*}{$\begin{array}{l}\mathrm{PVDF} / \mathrm{PET} \\
\text { based } \\
\text { composite }\end{array}$} & \multirow{4}{*}{$\begin{array}{l}\text { PVDF } \\
\text { phase }\end{array}$} & 5 & 142 & 4.5 & 0.76 & 76 \\
\hline & & 10 & 138 & 4.5 & 1.16 & 40 \\
\hline & & 20 & 134 & 5.3 & 1.26 & 24 \\
\hline & & 40 & 130 & 4.2 & 1.17 & 12 \\
\hline & \multirow{4}{*}{$\begin{array}{l}\text { PET } \\
\text { phase }\end{array}$} & 5 & 201 & 2.5 & 0.56 & 162 \\
\hline & & 10 & 199 & 3.2 & 0.82 & 102 \\
\hline & & 20 & 195 & 3.0 & 0.99 & 58 \\
\hline & & 40 & 190 & 3.4 & 1.05 & 32 \\
\hline
\end{tabular}

other hand, the values obtained for the non-isothermal crystallization rate show that they are not significantly affected by the presence of CB and GR additives inside the PVDF phase.

As in the case of isothermal crystallization, the crystallization rate under non-isothermal process was also evaluated by the half-time $t_{1 / 2}$ (Equation (3)), and the corresponding values are presented in Table 3 . As shown, the $t_{1 / 2}$ for PVDF and PET phases decreased with increasing the cooling rate, which is an indication that the crystallization process became quicker.

Another parameter, called the crystallization rate coefficient, $C R C$, given by the following relation could also be used to evaluate the crystallization kinetic under non-isothermal crystallization condition [17]:

$$
C R C=\frac{\Delta \phi(K / h)}{\Delta T_{c}(K)}
$$

This coefficient can be obtained directly from the slopes of the curves presented in Figure 8 and the corresponding values are respectively $-178 / \mathrm{h}$ and $-55 / \mathrm{h}$ for neat PVDF and neat PET, and respectively $-171 / \mathrm{h}$ and -188/h for PVDF and PET phases inside the conductive PVDF/PET based composite. These results show that the PVDF phase presents a lower $C R C$ than neat PVDF, which indicates a decrease in the crystallization rate, as predicted by the Avrami Equation.

\section{Conclusions}

In this work, we used the Avrami equation to study the isothermal and non-isothermal crystallization kinetics of $\mathrm{PVDF} / \mathrm{PET} / \mathrm{CB} / \mathrm{GR}$ conductive composite by using DSC characterization technique. Because PET isothermal crystallization was not observed, we only thought about the PVDF non-isothermal crystallization kinetics. It was found that the Avrami exponent did not changed in spite of treatment temperature. In $\mathrm{PVDF}_{\mathrm{PET} 190}, \mathrm{PVDF}_{\mathrm{PET} 180}$ and $\mathrm{PVDF}_{\mathrm{PET} 280}$, the higher the treatment temperature is, the quicker crystallization rate is. In any case, neat PVDF has the higher crystallization rate than that of PVDF phase inside PVDF PET190, $_{\text {PVDF }}$ PET180 $_{\text {and }}$ $\mathrm{PVDF}_{\mathrm{PET} 280}$ at the same crystallization temperature. The isothermal crystallization activation energy was also calculated to study the crystallization process.

In non-isothermal crystallization, the modified Avrami equation and the corresponding $C R C$ method were used. It was observed that the Avrami exponent did not change for neat PVDF and PVDF phase inside the conductive PVDF/PET based composite; however it decreased for both PVDF and PET phases inside the composite, compared with neat PVDF and PET. 


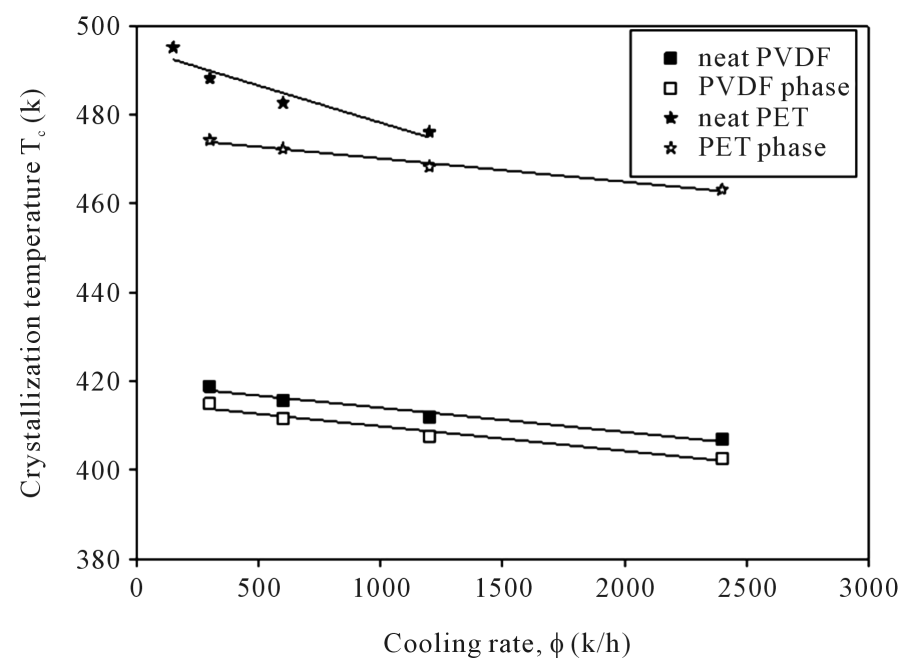

Figure 8. Crystallization temperature $T_{c}(K)$ as a function of the cooling rate, $\phi(K / h)$ for neat PET [18].

\section{Acknowledgements}

The authors are grateful to the Natural Sciences and Engineering Research Council of Canada (NSERC), as well as Jiangsu Government Scholarship for Overseas Studies (China).

\section{References}

[1] Song, J., Mighri, F. and Ajji, A. (2012) Polyvinylidene Fluoride/Poly(Ethylene Terephthalate) Conductive Composites for Proton Exchange Membrane Fuel Cell Bipolar Plates: Crystallization, Structure, and Through-Plane Electrical Resistivity. Polymer Engineering Science, 52, 2552-2558. http://dx.doi.org/10.1002/pen.23216

[2] Dhakate, S.R., Sharma, S., Borah, M., Mathur, R.B. and Dhami, T.L. (2008) Development and Characterization of Expanded Graphite-Based Nanocomposite as Bipolar Plate for Polymer Electrolyte Membrane Fuel Cells (PEMFCs). Energy and Fuels, 22, 3329-3334. http://dx.doi.org/10.1021/ef800135f

[3] Antunes, R.A., Oliveira, M.C.L. and Ett, G. (2011) Investigation on the Corrosion Resistance of Carbon BlackGraphite-Poly(Vinylidene Fluoride) Composite Bipolar Plates for Polymer Electrolyte Membrane Fuel Cells. International Journal of Hydrogen Energy, 36, 12474-12485. http://dx.doi.org/10.1016/j.ijhydene.2011.06.131

[4] Du, C., Ming, P., Hou, M., Fu, J., Shen, Q., Liang, D., Fu, Y., Luo, X., Shao, Z. and Yi, B. (2010) Preparation and Properties of Thin Epoxy/Compressed Expanded Graphite Composites Bipolar Plates for Proton Exchange Membrane Fuel Cells. Journal of Power Sources, 195, 794-800. http://dx.doi.org/10.1016/j.jpowsour.2009.08.033

[5] Yousefi, A.A. (2011) Influence of Polymer Blending on Crystalline Structure of Polyvinylidene Fluoride. Iranian Polymer Journal, 20, 109-121.

[6] Freirea, E., Bianchib, O., Martinsb, J.N., Monteirod, E.E.C. and Fortee, M.M.C. (2012) Non-Isothermal Crystallization of PVDF/PMMA Blends Processed in Low and High Shear Mixers. Journal of Non-Crystalline Solids, 358, 26742681. http://dx.doi.org/10.1016/j.jnoncrysol.2012.06.021

[7] Wu, M. and Shaw, L.L. (2004) On the Improved Properties of Injection-Molded, Carbon Nanotube-Filled PET/PVDF Blends. Journal of Power Sources, 136, 37-44. http://dx.doi.org/10.1016/j.jpowsour.2004.04.016

[8] Jeong Ho, K., Kwonsang, S. and Minho, L. (2014) Properties of Nanocomposites Based on Polymer Blend Containing PVDF, Carbon Fiber and Carbon Nanotube. Applied Chemistry for Engineering, 25, 14-19. http://dx.doi.org/10.14478/ace.2013.1068

[9] Avrami, M. (1939) Kinetics of Phase Change. II. Transformation-Time Relations for Random Distribution of Nuclei. Journal of Chemistry Physics, 8, 212-224. http://dx.doi.org/10.1063/1.1750631

[10] Avrami, M. (1939) Kinetics of Phase Change. I. General Theory. Journal of Chemistry Physics, 7, 1103-1112. http://dx.doi.org/10.1063/1.1750380

[11] Calcagno, C.I.W., Mariana, C.M., Teixeira, S.R. and Mauler, R.S. (2007) The Effect of Organic Modifier of the Clay on Morphology and Crystallization Properties of PET Nanocomposites. Polymer, 48, 966-974. http://dx.doi.org/10.1016/j.polymer.2006.12.044 
[12] Jeziorny, A. (1978) Parameters Characterizing the Kinetics of the Non-Isothermal Crystallization of Poly(Ethylene Terephthalate) Determined by DSC. Polymer, 19, 1142-1144. http://dx.doi.org/10.1016/0032-3861(78)90060-5

[13] Nguyen, L., Mighri, F. and Elkoun, S. (2010) Conductive Materials for Proton Exchange Membrane Fuel Cell Bipolar Plates Made from PVDF, PET and Co-Continuous PVDF/PET Filled with Carbon Additives. Fuel Cells, 10, 938-948. http://dx.doi.org/10.1002/fuce.200900171

[14] Song, J., Lu, C., Xu, D., Ni, Y., Liu, Y., Xu, Z. and Liu, J. (2010) The Effect of Lanthanum Oxide $\left(\mathrm{La}_{2} \mathrm{O}_{3}\right)$ on the Structure and Crystallization of Poly(Vinylidene Fluoride). Polymer International, 59, 954-960. http://dx.doi.org/10.1002/pi.2812

[15] Ding, Q., Dai, W.L. and Zhang, P. (2007) The Effect of Polyvinylidene Fluoride on Nonisothermal Crystallization Behavior of Polyoxymethylene. Polymer Engineering and Science, 47, 2034-2040. http://dx.doi.org/10.1002/pen.20916

[16] Hao, W.T., Wang, X.M., Yang, W. and Zheng, K. (2012) Non-Isothermal Crystallization Kinetics of Recycled PET$\mathrm{Si}_{3} \mathrm{~N}_{4}$ Nanocomposites. Polymer Testing, 31, 110-116. http://dx.doi.org/10.1016/j.polymertesting.2011.10.003

[17] Khanna, Y.P. (1990) A Barometer of Crystallization Rates of Polymeric Materials. Polymer Engineering and Science, 30, 1615-1619. http://dx.doi.org/10.1002/pen.760302410

[18] Ge, C., Shi, L., Yang, H. and Tang, S (2010) Nonisothermal Melt Crystallization Kinetics of Poly(Ethylene Terephthalate)/Barite Nanocomposites. Polymer Composites, 31, 1504-1514. http://dx.doi.org/10.1002/pc.20937 